Ojos claros y serenos, tan lindos para mirados, si miráis, miradme airados y no me miréis agenos ${ }^{12}$.

Citemos, por último, esta lejana reminiscencia en la comedia de don Francisco de Rojas Zorrilla Lo que quería ver el marqués de Villena ${ }^{13}$ :

ojos de mis ojos bellos,

Mi bien,

ya que alumbráis, no ceguéis;

y pues os dejáis amar, ojos míos, dejaos ver.

Juan Bautista Avalle-Arge

Harvard University.

\title{
ADICIÓN A "THREE CENTURIES OF TIRSO DE MOLINA" DE ALICE H. BUSHEE
}

Los muy valiosos estudios de Miss Bushee sobre las cinco Partes de Tirso y sobre la edición Guzmán de sus comedias son esmerados y minu$\operatorname{ciosos}^{1}$. Sin embargo, al recapitular las investigàciones de anteriores estudiosos parece haber pasado por alto una fuente italiana de materiales utilizables. Nos referimos a la monografía de Antonio Restori sobre Comedias de diferentes autores de la Biblioteca Palatina-Parmense, publicada hace más de sesenta años ${ }^{2}$. La monografía es difícil de encontrar; he tenido la suerte de ver el ejemplar personal de mi amigo el Prof. Claude Anibal. En su trabajo, Restori describe ochenta y siete volúmenes de comedias, zarzuelas y autos existentes en la Biblioteca. Doce de los tomos son de manuscritos, dieciséis son en parte de manuscritos y en parte de versiones impresas, y todos los tomos restantes son de ediciones impresas. Dice Restori (pág. 3) que "Ia collezione comprende più di ottocento tra zarzuelas e commedie, delle quali circa un centenaio e mezzo anonime, le altre inegualmente ripartite tra più di duecentoveinti autori”. La mayor parte de las comedias, añade (pág. 5 ), son sueltas.

Las obras de Tirso de Molina se enumeran en las págs. I08-i i2; son comedias seguramente suyas o que se le han atribuído. Se mencionan

Foulché-Delbosc) en Floresta general, Bibliófilos Madrileños, Madrid, 1910, I, pág. 264 .

12 Reeditada en Barcelona, I885, pág. 49

13 BAAEE, LIV, pág. 34I c.

1 Aliae H. Bushee, Three centuries of Tirso de Molina, Philadelphia, 1939, caps. Iv y v.

2 Antonio Restori, La collezione CC $C^{*}$ IV. 28033 della Biblioteca PalatinaParmense. Comedias de diferentes autores, en Studj di Filologia Romanza pubblicati da Ernesto Monaci, fasc. 15, Roma, I89I. 
catorce sueltas: Los amantes de Teruel, Amar por señas, El amor y la la amistad: Prueba real para conocer los verdaderos amantes y amigos, El burlador de Sevilla y Combidado de Piedra, El caballero de Gracia, Esto si que es negociar, El honroso atrevimiento, Los lagos de San Vicente, Quien calla otorga, La república al revés, El rey don Pedro en Madrid y Ynfançon en Illescas, La Santa Juana, $1^{\text {ra }}$ parte, La venganza de Thamar, La ventura con el nombre. Hay, además, tres manuscritos: Obligaciones de honor y Nimpha del Cielo, La romera de Santiago, Los valcones de Madrid. Hay también tres volúmenes de obras que Restori describe en las págs. I I o y sigs. ${ }^{3}$. El primero de los tres -rotulado $\mathrm{CC}^{*}$ III 28052- es un ejemplar de la Primera Parte valenciana de Tirso; Ruth Lee Kennedy ya ha llamado la atención sobre su existencia (en su reseña de Three centuries ..., HR, VIII, 83-85). Dice Restori de los otros dos volúmenes:

"Il $2^{\circ}$ e il $3^{\circ}$ appartengono a una collezione di sueltas ...Tra il 1720 e il I 736 la Sra. Teresa [de] Guzman (Madrid, Lonja de Comedias, Pta. del Sol) pubblicò moltissime sueltas di Tirso. Pensò poi di riunirle sotto un frontispizio e una copertina comune; anche questa collezione è curiosa perché ogni fascicolo ha diverse approvazioni, e alcuno ha la numerazione delle pagine e altri no; ma al meno provengono tutti della stessa libreria e hanno lo stesso formato; i pochi datati sono del i 734. Riferisco l'intestazione perché non fu

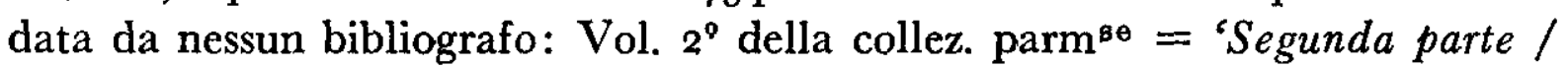
de las / Comedias / Verdaderas / Del Maestro de las Ciencias / Don Miguel / Tirso de Molina. / Tercera Impression.-Con privilegio - En Madrid: año de M.D.CC.XXXVI.-En la Lonja de Comedias de $D^{\mathrm{a}}$ Theresa / de Guzman, Puerta del Sol"”.

A continuación, Restori enumera las doce obras del Indice; son las mismas del "Tomo Segundo", pág. 73 de Bushee. (Bushee nos recuerda en la pág. 72 que ha tomado la lista de La batalla del honor de Lope; esta obra se anunció en la Gaceta en I735.)

Así, pues, la Biblioteca Palatina-Parmense tiene un ejemplar del segundo volumen de la edición Guzmán de Tirso ${ }^{4}$. Bushee nos dice (pág. 77) que la Bibliothèque Nationale de París y la Biblioteca del Palacio, de Madrid, también tienen ejemplares ${ }^{5}$. Al parecer, el ejemplar de la Palatina-Parmense es exactamente igual al de la Bibliothèque Nationale, pero (Bushee, pág. 78) el ejemplar de la Biblioteca del Palacio se diferencia de éstos en que tiene otras dos comedias encuadernadas con los doce originales. Son las Amazonas en las Indias y hazañas de los Pizarros y Antona García, ambas catalogadas como pertenecientes al "Tomo Tercero" (véase más abajo).

Restori (pág. I I I) describe así el tercer volumen: "ha lo stesso fron-

${ }^{3}$ La Biblioteca tiene, además de las comedias, una edición de 163 I de Los cigarrales de Toledo y una de 1635 de Deleytar aprovechando.

* La Segunda Parte de doña Teresa no debe confundirse con la Segunda Parte del propio Tirso, del siglo anterior.

5 Hay muchas sueltas de la edición de Guzmán sin encuadernar; cf. Bushee, pág. 79. 
tispizio [que el volumen II], tranne che invece di Segunda Parte, dice: Tercera Parte" ${ }^{\text {. }}$. Esta Tercera Parte de Guzmán no hay que confundirla, desde luego, con la Tercera Parte del mismo Tirso, de 1634 . Su existencia en la Biblioteca Palatina-Parmense adquiere gran importancia puesto que sólo se conoce otro ejemplar, el de la Bibliothèque Nationale (Bushee, pág. 77) ${ }^{7}$.

Continuando su descripción, Restori enumera once comedias y un auto del Indice de la Tercera Parte. En sus primeros nueve títulos, esta lista coincide con la del "Tomo Tercero" de Bushee, pág. 73; esta lista, como hemos visto, ha sido tomada de La batalla del honor de Lope. Como títulos I0, II y I2, Restori nos da: Engañar con la verdad y Desde Toledo a Madrid, Santo y sastre y El colmenero divino (éste es el auto). Estas tres obras no estaban anunciadas en la lista de La batalla del honor. Dice Restori (pág. i I 2 ) que las comedias 9, 10 y i I han sido arrancadas del volumen de la Palatina-Parmense ("i numeri 9, ro e I I furono strappati dal volume"), de suerte que sólo tiene nueve comedias. Es el mismo número que se anuncia para el "Tomo Tercero", pero los títulos son diferentes: en el "Tomo Tercero" faltan El colmenero divino del ejemplar de la Palatina-Parmense, y en ésta falta Antona García, que aparece en el "Tomo Tercero". Así, pues, el ejemplar de la PalatinaParmense es imperfecto; también lo es el de la Bibliothèque Nationale; Bushee lo describe en la pág. 78 de su trabajo.

Podemos corregir hasta cierto punto la tabla que presenta Bushee en la pág. 8o a la luz del ejemplar de la Palatina-Parmense: en el III, mantenemos el número 2 para la Tercera Parte (se trata de La Nuera más leal y mejor espigadera y La elección por la virtud). El número 6 de la Quarta Parte debe cambiarse en 5 para el ejemplar de la PalatinaParmense; se trata de las comedias Favorecer a todos ..., Todo es dar en una cosa, Amazonas en las Indias, La lealtad contra la envidia y La peña de Francia. Se mantiene el número I para la Quinta Parte (la comedia es Escarmientos para el cuerdo). A G.C. y Cig. podemos añadir D.A. (Deleytar aprovechando); de este volumen es de donde procede El colmenero divino.

De pasada, notamos que el número de 2000 sueltas que da Restori para Teresa de Guzmán es sustituído por un número más modesto por Bushee. Dice Restori (pág. 7) que "nella Lonja de las comedias a la Puerta del Sol en Madrid, tenuta verso il I $73^{\circ}$ da $\mathrm{D}^{\mathrm{a}}$ Teresa de Guzman, si vendevano com'è detto sulla copertina di una suelta del padre Tellez (Tirso), mas de dos mil comedias, autos ecc." Bushee (pág. 72 ), citando a Teresa de Guzmán, menciona "muchos entremeses, Relaciones y más de seiscientos titulos de surtimiento de Comedias". Tal vez sea posible

6 Si tomamos las palabras de Restori en su sentido literal, resulta que la Tercera Parte de la edición Guzmán tiene exactamente el mismo título que la Segunda Parte de Tirso: "Maestro de las Ciencias Don Miguel Tirso de Molina". Bushee habla de este curioso modo de llamar a Tirso en las págs. 75 y 79 . En esta última admite que el título se aplica a la Segunda Parte, pero da a entender que la Tercera Parte no lo lleva.

7 La primera de las Partes de la edición Guzmán, la que Bushee llama "Tomo Primero", no aparece en la Biblioteca Palatina-Parmense. 
conciliar las dos afirmaciones suponiendo que la cantidad de dos mil incluye obras de todo tipo, mientras que "más de seiscientos" parece referirse sólo a comedias.

University of Tennessee.

Gerald E. Wade

\section{"Of ... ASTROLOGÍA"}

"Oí... astrología" (La verdad sospechosa, $\mathrm{I}, 3$ ) es frase que se ha interpretado literalmente en todas las ediciones críticas de la comedia que he podido consultar ${ }^{1}$.

Después de un discurso en que el gracioso Tristán compara las mujeres de la corte con los astros del sistema de Ptolomeo, don García le pregunta,

$$
\text { ¿Eres astrólogo? }
$$

Tristán responde:

$$
\text { Oí, }
$$

el tiempo que pretendía

en palacio, astrología ${ }^{2}$.

Alarcón, como Tristán, era pretendiente. Conocía la burocracia de funcionarios y privados que también se habían hecho astrólogos para poder augurar los gustos del monarca según la expresión de su cara. Y Alarcón les compadecía:

$$
\begin{aligned}
& \text { ¡Fuerte caso, dura ley, } \\
& \text { que haya de ser el privado } \\
& \text { un astrólogo, colgado } \\
& \text { de los aspectos del rey! }{ }^{3}
\end{aligned}
$$

El, a su vez, podía repetir con el autor anónimo de la Epistola moral a Fabio:

Triste de aquel que vive destinado

a esa antigua colonia de los vicios

augur de los semblantes del privado4.

1 "Oir era asistir a clase...", Alfonso Reyes, Ruiz de Alarcón. Teatro, Madrid: Clás. Cast. vol. 37, 1948, pág. I6; "I studied astrology while I was seeking a government position", ARTHUR L. OWEN, La verdad sospechosa, Bostoll, I928, pág. 125; " ...oír astrología équivaut à être étudiant en astrologie”, Ed. BARRY, La verdad sospechosa, París, 1897, pág. 24; "Oír: 'estudiar" ", P. Henrí́uez Ureña y J. Bogliano, La verdad sospechosa, Buenos Aires, I939, pág. 36; "Oír: Etudier sous un Man̂tre une matière, suivre des cours de ...", G. DELPY y S. Denis, La verdad sospechosa, París, 1947, pág. 21 .

$2 B A A E E$, XX, pág. 323 a.

3 BAAEE, XX, pág. I Ib.

4 The Oxford Book of Spanish Verse, Oxford, 1920, pág. 163. 